\title{
Nimotuzumab prolongs survival in patients with malignant gliomas: A phase I/II clinical study of concomitant radiochemotherapy with or without nimotuzumab
}

\author{
JIDONG HONG ${ }^{1}$, YUPING PENG ${ }^{1}$, YUPING LIAO ${ }^{1}$, WUZHONG JIANG ${ }^{1}$, RUI WEI ${ }^{1}$, \\ LEI HUO $^{2}$, ZAIDE HAN $^{3}, \mathrm{CHAOJUN} \mathrm{DUAN}^{4}$ and MEIZUO ZHONG ${ }^{1}$ \\ Departments of ${ }^{1}$ Oncology, ${ }^{2}$ Neurosurgery and ${ }^{3}$ Radiology and ${ }^{4}$ Institute of Medical Sciences, \\ The Xiangya Hospital of Central South University, Changsha 410008, P.R. China
}

Received February 10, 2012; Accepted April 13, 2012

DOI: $10.3892 / \mathrm{etm} .2012 .555$

\begin{abstract}
The present study aimed to determine whether nimotuzumab enhances the effect of radiochemotherapy in malignant gliomas. Patients $(n=41)$ with malignant gliomas were divided into 20 cases (treatment group) in which nimotuzumab plus radiochemotherapy were offered and 21 cases (control group) in which placebo and radiochemotherapy were administered to the patients. The response to treatment was evaluated according to the Response Evaluation Criteria in Solid Tumors, the Kaplan-Meier method was used to calculate the mean and median survival times and 1-year survival rate, and the log-rank test and the Chi-square test were used to analyze the difference in the survival and response rate between the treatment and control groups. The mean survival times of the treatment and control groups were 14.3 and 10.4 months and the median survival times of the treatment and control groups were 16.5 and 10.5 months, respectively. The 1-year survival rates of the treatment and control groups were 81.3 and $69.1 \%$, respectively, with no significant difference $(\mathrm{P}>0.05)$. The objective response rates of the treatment and control groups were 70.0 and $52.4 \%$, respectively, with no significant difference $(\mathrm{P}>0.05)$. In conclusion, there was a trend towards improved treatment efficacy of radiochemotherapy combined with nimotuzumab against malignant gliomas. This study demonstrated that the use of nimotuzumab combined with radiotherapy and concomitant temozolomide chemotherapy is effective for malignant gliomas.
\end{abstract}

\section{Introduction}

Gliomas account for half of all primary intracranial tumors (1). High-grade gliomas are those gliomas of grades III-IV, also

Correspondence to: Professor Meizuo Zhong, Department of Oncology, The Xiangya Hospital of Central South University, 87 Xiangya Road, Changsha 410008, P.R. China

E-mail:mei_zuo_zhong@126.com

Key words: malignant gliomas, nimotuzumab, temozolomide, radiotherapy known as malignant gliomas with poor prognosis. Glioblastoma multiforme is the most malignant of the astrocytic tumors, which belong to the grade IV gliomas. The goal of therapy in malignant gliomas is dependent on available techniques and on the nature of the malignant glioma itself, and the final objective of malignant glioma therapy is cytoreduction. Multimodality therapy including surgery, radiotherapy and chemotherapy can treat malignant gliomas, but rarely cures them. Surgery can establish a diagnosis and remove the tumor, improving the symptoms, but the role of surgical resection in treatment of malignant gliomas remains controversial even after 75 years of experience (2). There is evidence that surgical reduction of the tumor to minimal residual amounts is associated with prolonged survival. In one Brain Tumor Cooperative Group study, CT scans from brain tumor patients were studied several times over the course of their illness and compared to their ultimate outcomes (3). There was a marked inverse correlation between postoperative tumor size and survival. This was especially notable in patients with minimal or no residual enhancing tumor. The beneficial effect of surgery was less marked where the aim was de-bulking as opposed to leaving a minimal amount of residual tumor. A trend toward longer survival was observed in patients whose tumors were reduced by $75 \%$ or more. A similar result was reported in a study carried out by MRI (4). Retrospective reviews have indicated that surgery increases survival time in malignant glioma patients (5). Radiation Therapy Oncology Group data have indicated that surgical resection was associated with statistically significantly longer survival and median survival time (6).

Radiotherapy is a key treatment for malignant gliomas. The Brain Tumor Study Group first reported in controlled studies that whole-brain radiation therapy increases the survival time of patients over those following surgery alone (7). Other data showed that patients receiving 55-60 Gy survive for significantly longer than those receiving $50 \mathrm{~Gy}$ or less (8). Andersen et al reported that postoperative radiotherapy improved the 6-month and 1-year survival rates of glioblastoma patients (9). Kristiansen et al studied 118 patients with supratentorial astrocytoma of grades III-IV and revealed that postoperative radiotherapy prolonged the median survival time to 10.8 months vs. 5.2 months in the control group (10). 
Laperriere et al reviewed systemic trials of postoperative radiotherapy on malignant gliomas and carried out a metaanalysis. Their results revealed that six randomized trials detected a significant survival benefit favoring post-operative radiotherapy compared with no radiotherapy (11).

Temozolomide (TMZ) is an oral preparation used in newly diagnosed grade III and IV gliomas as adjuvant and concomitant therapy to surgery and radiotherapy. It has the advantages of being administered orally and exhibiting effective blood-brain barrier (BBB) penetration, and may have low toxicity (12). Watkins et al reported that among glioblastoma patients, TMZ provided a statistically significant survival improvement over no chemotherapy (median survival 12.7 vs. 7.5 months; $\mathrm{P}=0.0058$ ) (13). Stupp et al reported the overall survival was $27.2 \%$ (95\% CI, 22.2-32.5) at 2 years, $16.0 \%(12.0-20.6)$ at 3 years, $12.1 \%(8.5-16.4)$ at 4 years, and $9.8 \%(6.4-14.0)$ at 5 years with TMZ plus radiotherapy, versus $10.9 \%$ (7.6-14.8), 4.4\% (2.4-7.2), $3.0 \%(1.4-5.7)$, and $1.9 \%(0.6-4.4)$ with radiotherapy alone (HR 0.6; 95\% CI, 0.5-0.7; P<0.0001) (14).

Nimotuzumab is a humanized monoclonal antibody that inhibits tumor cells and enhances chemoradiosensitivity, and has already been used in combination with radiotherapy in unresectable head and neck cancer patients $(15,16)$. A trend towards survival benefit for nimotuzumab-treated subjects has been identified. Malignant gliomas are resistant to radiotherapy and chemotherapy, and since the majority of patients with malignant gliomas experience local recurrence, the prognosis of patients with this tumor remains dismal. Therefore, we designed randomly controlled trials to investigate the effect of nimotuzumab on sensitization to the effect of radiochemotherapy on malignant gliomas.

\section{Materials and methods}

Patient selection. Between June 2008 and February 2011, 41 patients with malignant gliomas confirmed by pathological diagnosis according to the World Health Organization criteria (17) who had not received prior treatment were eligible to take part in the study. They were divided into the nimotuzumab + radiochemotherapy (treatment group; 20 cases) and placebo + radiochemotherapy (control group; 21 cases) groups. All patients provided written informed consent. The protocols were approved by the Institutional Research Review Board at Xiangya Hospital of South Central University, Changsha, China. Eligibility criteria comprised the following: age $\geq 18$ years; Karnofsky performance status (KPS) score $\geq 60 \%$; grade III-IV glioma confirmed by histopathology; predictive survival time $\geq 6$ months; normal function of major organs; bone marrow function: hemoglobin $\geq 10 \mathrm{~g} / 1$, white blood cell count $\geq 4 \times 10^{9} / 1$, platelet count $\geq 100 \times 10^{9} / 1$, normal renal function (serum creatinine, $1.2 \mathrm{mg} / \mathrm{dl}$ ); existing lesions measurable by MRI; and no allergic reaction to biological agents. Clinical data of the patients are shown in Table I.

Nimotuzumab treatment. In the radiotherapy period, the patients in the treatment group received $200 \mathrm{mg}$ intravenous nimotuzumab by drip, once per week, continuing for six weeks. Nimotuzumab $(200 \mathrm{mg}$ ) was dissolved in $250 \mathrm{ml}$ physiological saline. Infusion time was $>60$ minutes. Diphenhydramine (20 mg) was injected intramuscularly and dexamethasone
(10 mg) was infused intravenously to patients prior to nimotuzumab infusion for the first time. In the absence of an allergic reaction, diphenhydramine and dexamethasone were not administered in subsequent doses. In the control group, patients were administered placebo instead of nimotuzumab.

Chemotherapy. TMZ was used in conjunction with radiotherapy (RT) and was administered in two phases. During RT, a daily dose of $75 \mathrm{mg} / \mathrm{m}^{2}$ was administered. On completion of RT, there was a 28-day treatment break, followed by a second phase of up to six 28-day cycles of maintained (adjuvant) TMZ treatment. Dosage was $150 \mathrm{mg} / \mathrm{m}^{2}$ once daily for 5 days followed by 23 days without treatment. At the start of cycle 2 , the dose was escalated to $200 \mathrm{mg} / \mathrm{m}^{2} /$ day if haematological toxicity was within prescribed limits.

Radiotherapy. All patients were treated with intensity modulated radiotherapy (IMRT) or three-dimensional conformal radiotherapy (3D-CRT). Each patient was positioned and immobilized with an individualized thermoplastic mask with treatment-planning CT. Slices of $0.3 \mathrm{~cm}$ were obtained through the regions of interest. Gross tumor volume (GTV), clinical tumor volume (CTV), and planning tumor volume (PTV) were defined based on the treatment-planning $\mathrm{CT}$, with registration to MRI when possible, in accordance with the International Commission on Radiation Units and Measurements 62 report (1999), according to pre- and postoperative MRI. Gross tumor volume (GTV) or gross tumor volume tumor bed (GTVtb) were delineated on contrasted MRI images. GTV or GTVtb with a $2.5-3.0 \mathrm{~cm}$ margin were defined as clinical tumor volume (CTV). CTV with 0.3-0.5 cm margins were defined as planning tumor volume (PTV); GTV or GTVtb with a $0.5-\mathrm{cm}$ margin were defined as planning GTV (PGTV) or planning GTVtb (PGTVtb); 3D-CRT or IMRT were delivered as $\mathrm{D}_{\mathrm{T}}=46-50 \mathrm{~Gy} / 26-28$ fractions to PTV or $\mathrm{D}_{\mathrm{T}}=54-66 \mathrm{~Gy} / 26-30$ fractions to PGTV or PGTVtb; dose was in part determined by critical structure tolerance.

Evaluation response. All patients were surgically treated with exploratory craniotomy, tumorectomy and/or biopsy, and the extent of surgical resection was evaluated by preoperative MRI, the patient surgical record and the results of the last three-day postoperative MRI. Based on this, patients were allocated total resection, subtotal resection or biopsy procedures. Total resection represented the complete removal of the visible tumor, subtotal resection involved a 50-99\% volume reduction and a biopsy indicated a $<50 \%$ resection. Objective response rates of the treatment group and control group were evaluated using the Response Evaluation Criteria in Solid Tumors (18). Complete response (CR) was defined as disappearance of all target lesions. Partial response (PR) was defined as a decrease of at least $30 \%$ in the sum of diameters of target lesions, taking as reference the baseline sum diameters. Progressive disease (PD) was defined as an increase of at least $20 \%$ in the sum of diameters of target lesions, taking as reference the smallest sum on study. Stable disease (SD) was defined as neither sufficient shrinkage to qualify for PR nor sufficient increase to qualify for PD, taking as reference the smallest sum diameters while on study. Surgical resection extent and response rate were determined by comparing the 
Table I. Clinical data of patients in the treatment group and control group.

\begin{tabular}{|c|c|c|c|c|}
\hline Characteristics & $\begin{array}{c}\text { Treatment } \\
\mathrm{n}(\%)\end{array}$ & $\begin{array}{c}\text { Control } \\
\mathrm{n}(\%)\end{array}$ & $\mathrm{Z}$ & P-value \\
\hline Total & $20(100)$ & $21(100)$ & & \\
\hline \multicolumn{5}{|l|}{ Gender } \\
\hline Male & $14(70)$ & $12(57.1)$ & -0.111 & 0.912 \\
\hline Female & $6(30)$ & $9(42.9)$ & & \\
\hline \multicolumn{5}{|l|}{ Age } \\
\hline$<40$ years & $7(35)$ & $9(42.9)$ & -0.146 & 0.990 \\
\hline $40-60$ years & $12(60)$ & $11(52.4)$ & & \\
\hline$>60$ years & 1 (1) & 1 (4.7) & & \\
\hline \multicolumn{5}{|l|}{ Lesion location } \\
\hline Temporal lobe & $3(15)$ & $5(23.8)$ & 0.227 & 0.821 \\
\hline Parietal lobe & $5(25)$ & $6(28.6)$ & & \\
\hline Frontal lobe & $5(25)$ & $4(19.0)$ & & \\
\hline Occipital lobe & $4(20)$ & $3(14.3)$ & & \\
\hline Brain stem & $2(10)$ & $3(14.3)$ & & \\
\hline Two or more than two locations & $1(5)$ & $0 \quad(0)$ & & \\
\hline \multicolumn{5}{|l|}{ Lesion side } \\
\hline Left & $6(30)$ & $10(47.6)$ & -0.776 & 0.438 \\
\hline Right & $12(60)$ & $8(38.1)$ & & \\
\hline Both sides & $2(10)$ & $3(14.3)$ & & \\
\hline \multicolumn{5}{|l|}{ Extent of surgical resection } \\
\hline Total resection & $4(20)$ & $6(28.6)$ & -0.495 & 0.621 \\
\hline Subtotal resection & $13(65)$ & $12(57.1)$ & & \\
\hline Biopsy & $3(15)$ & $3(14.3)$ & & \\
\hline \multicolumn{5}{|c|}{ Interval between surgery and radiotherapy } \\
\hline$\leq 1$ month & $10(50)$ & $8 \quad(38)$ & -0.483 & 0.629 \\
\hline$>1$ month & $10(50)$ & $13 \quad(62)$ & & \\
\hline \multicolumn{5}{|l|}{ Histological grade } \\
\hline III & $9(45)$ & $8(38.1)$ & -0.814 & 0.415 \\
\hline IV & $4(20)$ & $3(14.3)$ & & \\
\hline III-IV ${ }^{\mathrm{a}}$ & $7(35)$ & $10(47.6)$ & & \\
\hline \multicolumn{5}{|l|}{ Modality of radiotherapy } \\
\hline 3D-CRT & $2(10)$ & 4 (19) & -0.809 & 0.418 \\
\hline IMRT & $18(90)$ & $17 \quad(81)$ & & \\
\hline \multicolumn{5}{|l|}{ Dose of radiotherapy } \\
\hline$<54$ Gy & $3(15)$ & $6(28.6)$ & -0.637 & 0.524 \\
\hline 54-60 Gy & $10(50)$ & $9(42.8)$ & & \\
\hline$>60 \mathrm{~Gy}$ & $7(35)$ & $6(28.6)$ & & \\
\hline
\end{tabular}

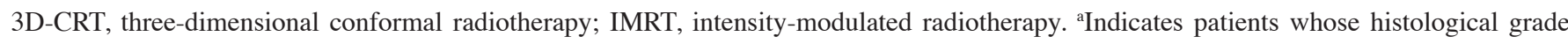
could not be accurately classified.

disease lesion of the enhancing tumor on gadolinium-enhanced T1-weighted MR images at points preoperative and postoperative (within 3 days following surgery) or after completion of the radiotherapy. Response rate included complete response and partial response. Enhanced disease lesion in gadoliniumenhanced T1-weighted MR images was regarded as the basis of tumor residual and tumor recurrence. The follow-up period began on completion of radiotherapy. The MRI was scanned every three months following radiotherapy to evaluate tumor relapse.

Statistical analysis. SPSS 13.0 was used to carry out the statistical analysis. The mean and median survival times and 1-year survival rate were calculated using the Kaplan-Meier method. Mean and median survival times and 1-year survival rate between the treatment group and control group were 


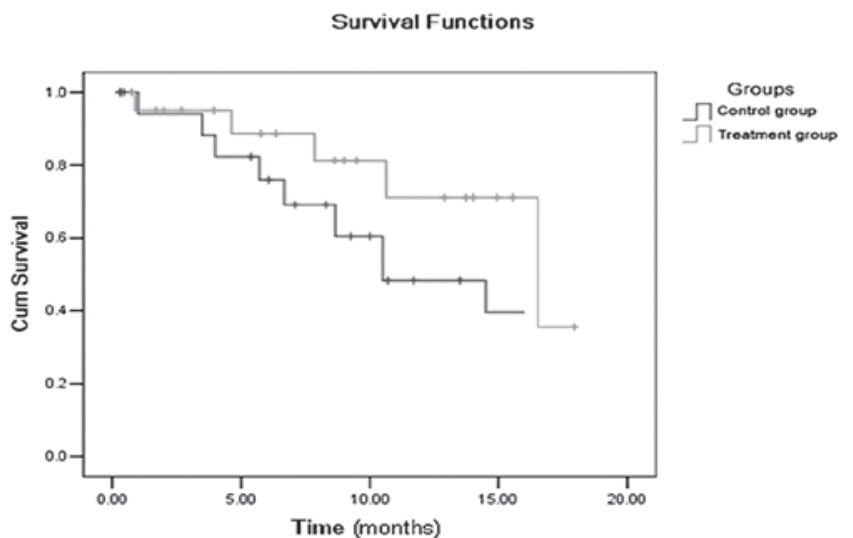

Figure 1. The survival curves of the treatment and control groups.
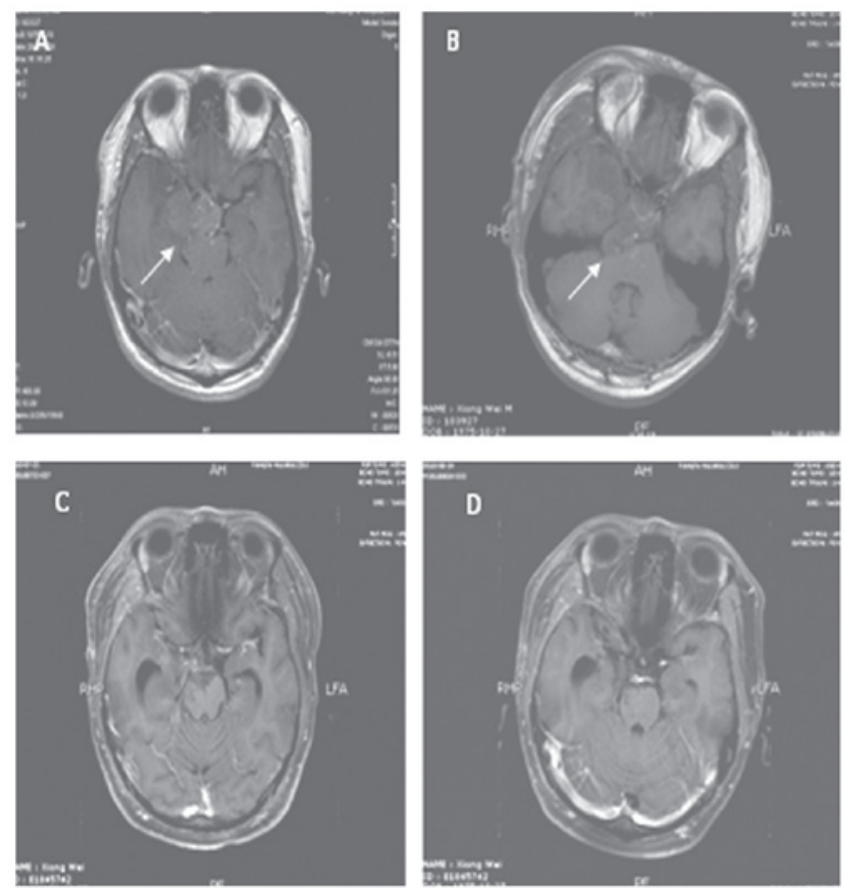

Figure 2. MRI from a case with grade III glioma in the control group. The lesion was located in the right temporal lobe and hippocampus and intruded suprasellar cistern with slight enhancement. The tumor size was $5 \times 4 \mathrm{~cm}$ and the surrounding peritumor edema was mild. (A) Contrasted T1 image prior to surgery. (B) Contrasted $\mathrm{T} 1$ image following surgery shows residual lesion. (C) Contrasted T1 image following postoperative radiotherapy shows CR. (D) Contrasted T1 image three months after radiotherapy shows no recurrent lesion.

compared using the log-rank method. The Wilcoxon rank sum test was used to apply the equilibrium analysis of the two groups' data. The difference in objective response rate between the treatment and control groups was evaluated using the Pearson Chi-square test. A p-value $<0.05$ was considered to indicate statistical significance in all statistical analyses.

\section{Results}

Survival in the treatment and control groups. Mean survival times of the treatment and control groups were 14.3 and
Table II. Objective response rate of patients in treatment and control groups.

\begin{tabular}{lcrccc}
\hline Group & CR & PR & SD & PD & RR (\%) \\
\hline Treatment & 3 & 11 & 4 & 2 & 70.0 \\
Control & 2 & 9 & 7 & 3 & 52.4 \\
\hline
\end{tabular}

$\chi^{2}=1.336 ; \mathrm{P}=0.248$. CR, complete response; PR, partial response; SD, stable disease; $\mathrm{PD}$, progressive disease; $\mathrm{RR}$, response rate.
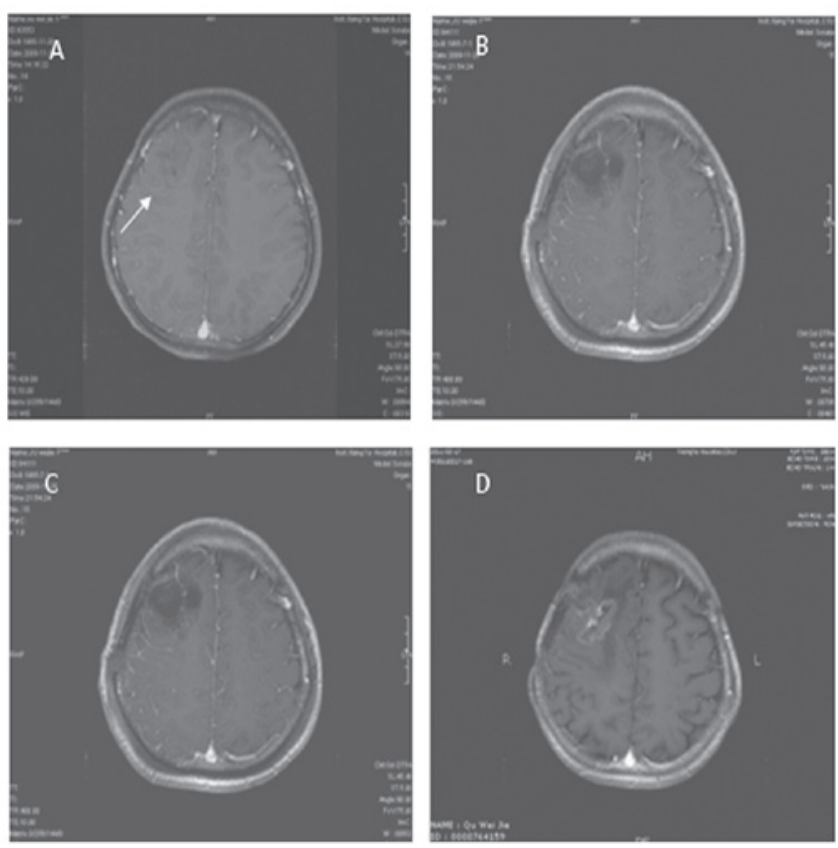

Figure 3. MRI from a case with grade III-IV glioma in the treatment group. The lesion was located in the right frontal lobe with mild enhancement. Tumor size was $4 \times 4 \mathrm{~cm}$ and the surrounding peritumor edema was not obvious. (A) Contrasted T1 image prior to surgery. (B) Contrasted T1 image following surgery shows total resection. (C) Contrasted T1 image following postoperative radiotherapy shows SD. (D) Contrasted T1 image one year following postoperative radiotherapy shows pseudoprogress.

10.4 months, respectively. Median survival times of the treatment and control groups were 16.5 and 10.5 months, respectively. The 1-year survival rates of the treatment and control groups were 81.3 and $69.1 \%$, respectively. Mean and median survival times of the treatment group were longer than those of control group, and the 1-year survival rate of the treatment group was higher than that of the control group. There was no significant differences between the treatment and control groups ( $\mathrm{P}=0.094$, Fig. 1). The gadolinium-enhanced T1-weighted MR images of representative patients are shown in Fig. 2-5.

Objective response rate of patients in the treatment and control groups. Objective response rates of the treatment and control groups were 70.0 and $52.4 \%$, respectively, and the difference between the treatment group and control group was not statistically significant $(\mathrm{P}=0.248$, Table II). 

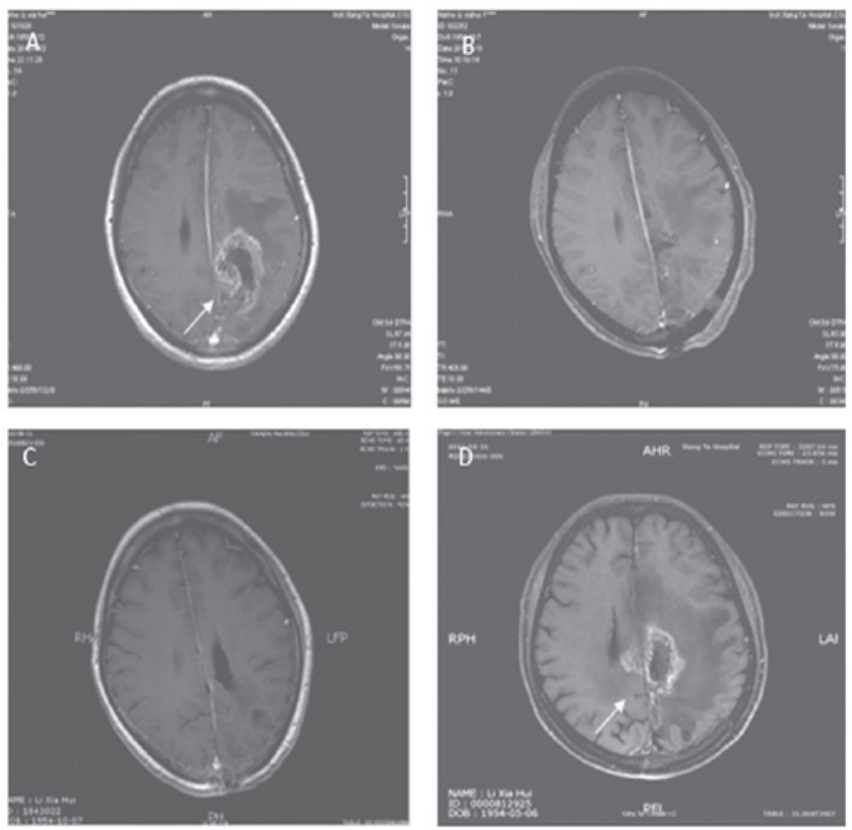

Figure 4. MRI from a case with grade III-IV glioma in the control group The lesion was located in the left parietal lobe with mid-range enhancement. Tumor size was $6 \times 5 \mathrm{~cm}$ and surrounding peri-tumor edema was marked. (A) Contrasted T1 image prior to surgery. (B) Contrasted T1 image following surgery shows total resection. (C) Contrasted T1 image following radiotherapy shows SD. (D) Contrasted T1 image 10 months after postoperative radiotherapy shows recurrent lesion.

\section{Discussion}

Malignant gliomas are aggressive and incurable brain tumors, and the aim of treatment is to increase survival while improving quality of life. Median survival is approximately one year for patients with grade IV tumors and 2-3 years for those with grade III tumors. More than $80 \%$ of high-grade gliomas recur within 2-3 cm of the margin of the original tumor following surgery (19). Recurrence can be defined clinically or radiologically, based on patients presenting with certain progressive symptoms (20).

The benefit of radiotherapy for malignant gliomas has been demonstrated. A postoperative 6-week course of external beam radiotherapy using linear accelerators is recommended as standard treatment (11). A systematic review of radiotherapy showed a 3-4-month survival advantage for postoperative radiotherapy compared with supportive care or chemotherapy (21). However, the outcome of simple postoperative radiotherapy in malignant gliomas is poor.

TMZ has been used for malignant gliomas. It has the advantage of being administered orally, has marked BBB penetration and may have low toxicity. TMZ (8-carbamoyl3-methylimidazo[5,1-d]-1,2,3,5-tetrazin-4 (3H)-1) is an oral prodrug, i.e., it is converted within the body into an active agent. In the case of TMZ, the substance produced is monomethyl triazenoimidazole carboxamide (MTIC). The effect of MTIC is believed to be the methylation of DNA in a manner that prevents the proliferation of tumor cells (12). It has been suggested that patients with reduced MGMT activity may derive particular benefit from TMZ, as their DNA is less capable of repairing the cytotoxic damage inflicted by the drug, thus preserving its
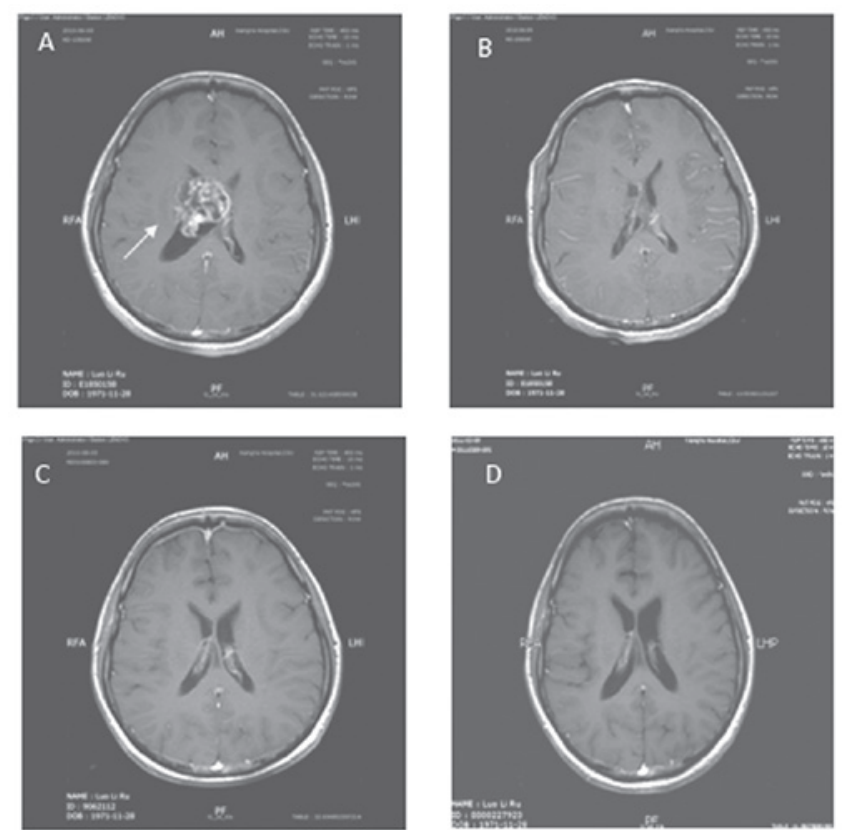

Figure 5. MRI from a case with grade IV glioma in the treatment group. The lesion was located in the body of the lateral cerebral ventricle. Tumor size was $5 \times 4 \mathrm{~cm}$ with uneven enhancement. Surrounding peri-tumor edema was not marked. (A) Contrasted T1 image prior to surgery (B) Contrasted T1 image following surgery shows total resection. (C) Contrasted T1 image following postoperative radiotherapy shows SD. (D) Contrasted T1 image seven months after postoperative radiotherapy shows no recurrent lesion.

effect (22-24). Surgery followed by RT with concomitant TMZ as a standard regimen has been used for malignant gliomas.

Nimotuzumab is a humanized anti-epidermal growth factor receptor (EGFR) monoclonal antibody (mAb) obtained by complementarity determining region grafting of a murine $\mathrm{mAb}$ to a human framework. Nimotuzumab binds to domain III of the extracellular region of the EGFR. Studies have shown that nimotuzumab mediates anti-tumor effects due to its capacity to inhibit proliferation, survival and angiogenesis and to induce apoptosis to cause antibody-dependent cell-mediated cytotoxicity and complement-dependent cytotoxicity (25). Malignant gliomas have been found to overexpress EGFR and to amplify the EGFR gene (26-28). EGFR has been associated with high malignant degree and poor outcomes in malignant gliomas. The BBB prevents certain chemotherapy drugs and large molecular substances from penetrating the brain tissue, and surgery, radiotherapy and the tumor itself disrupt BBB integrity (29-31). Radioimmunoscintigraphy with 99mTc-labelled nimotuzumab exhibits a high sensitivity, specificity and accuracy in in vivo detection of gliomas in patients (32). In a clinical trial involving high-grade gliomas treated with nimotuzumab combined with radiotherapy, radioimmunoscintigraphy with $99 \mathrm{mTc}$-labelled nimotuzumab showed patients achieving CR according to standard imaging methods and no murine anti-EGFR antibody uptake, whereas patients showing PR, SD or PD exhibited positive uptake of the murine anti-EGFR antibody in the known tumor areas (33). The above study indicated that nimotuzumab was capable of penetrating the BBB when it was disrupted by surgery, radiotherapy and/or the tumor itself, and of combining with EGFR to a certain extent and inhibiting its biological function. 
EGFR expression has been correlated with alterations in cell cycle progression (34), promotion of cell proliferation, enhancement of angiogenesis $(35,36)$, promotion of DNA radiation damage repair and decrease in apoptosis of tumor cells (37). When human cancer cells are exposed to ionizing radiation, the epidermal growth factor receptor (EGFR) is activated. This in turn mediates a cytoprotective response that reduces the sensitivity of the cells to ionizing radiation (38-40).

Our study revealed that the mean and median survival times of the patients with malignant gliomas were longer in those patients treated with nimotuzumab-combined radiochemotherapy. However, mean and median survival time and the one-year survival rate exhibited no significant difference between the treatment and control groups. The objective response rate between the treatment and control groups also exhibited no significant difference. We postulate that the sample size enrolled in our study was too small to detect any statistically significant difference in median survival time or objective response rate between the treatment and control groups. Although the patient numbers were small, there was a trend towards survival benefit with nimotuzumab and radiochemotherapy.

We hypothesize that the mechanism by which nimotuzumab enhances sensitivity of malignant gliomas to radiotherapy is the inhibition of proliferation and induction of apoptosis in malignant glioma cells. Diaz et al reported that exposure to nimotuzumab can inhibit proliferation and induce apoptosis in U87MG brain tumors, and observed enhancement of radiosensitivity of these tumors (41). Furthermore, certain studies have shown that anti-EGFR mAb inhibits angiogensis, downregulates vascular endothelial growth factor (VEGF) expression and enhances the radiosensitivity of tumor cells $(35,42,43)$. Anti-EGFR mAb also mediates radiosensitivity through DNA repair pathways. AntiEGFR $m A b$ triggered a specific physical interaction between internalized EGFR and DNA protein kinase (DNA-PK) in the cytosol, significantly reduced the level of DNA-PK in the nucleus and raised the level of DNA-PK in the cytosol. DNA-PK in the nucleus repairs double-strand DNA breakage, therefore it is proposed that anti-EGFR mAb-induced reduction of the DNA-PK in the nucleus sensitized the tumors to radiotherapy $(44,45)$. The capacity of anti-EGFR mAb to modulate tumor cell-cycle phase distribution may play an important role in enhancement of radiosensitivity. Anti-EGFR mAb may enhance radiosensitivity by inducing accumulation of cells in the more radiosensitive cell cycle $\mathrm{G} 1$ and $\mathrm{G} 2 / \mathrm{M}$ phases and reducing the size of the radioresistant S-phase fraction (46-48).

\section{Ackowledgements}

This work was supported by Hunan Province Development and Reform Committee Science Research Fund (2010-1060), Hunan Province Science and Technology Program (2011SK3223), the Project of New Clinic Techniques of Central South University, China and the National Natural Scientific Foundation of China (Nos. 30670990, 30871189 and 81071718).

\section{References}

1. Counsell CE and Grant R: Incidence studies of primary and secondary intracranial tumors: a systematic review of their methodology and results. J Neurooncol 37: 241-250, 1998.
2. Nazzaro JM and Neuwelt EA: The role of surgery in the management of supratentorial intermediate and high-grade astrocytomas in adults. J Neurosurg 73: 331-344, 1990.

3. Wood JR, Green SB and Shapiro WR: The prognostic importance of tumor size in malignant gliomas: a computed tomographic scan study by the Brain Tumor Cooperative Group. J Clin Oncol 6: 338-343, 1988.

4. Albert FK, Forsting M, Sartor K, Adams HP and Kunze S: Early postoperative magnetic resonance imaging after resection of malignant glioma: objective evaluation of residual tumor and its influence on regrowth and prognosis. Neurosurgery 34: 45-61, 1994.

5. Devaux BC, O'Fallon JR and Kelly PJ: Resection, biopsy, and survival in malignant glial neoplasms. A retrospective study of clinical parameters, therapy, and outcome. J Neurosurg 78: 767-775, 1993.

6. Curran WJ Jr, Scott CB, Horton J, et al: Does extent of surgery influence outcome for astrocytoma with atypical or anaplastic foci (AAF)? A report from three Radiation Therapy Oncology Group (RTOG) trials. J Neurooncol 12: 219-227, 1992.

7. Walker MD, Alexander E Jr, Hun WE, et al: Evaluation of BCNU and/or radiotherapy in the treatment of anaplastic gliomas. A cooperative clinical trial. J Neurosurg 49: 333-343, 1978.

8. Walker MD, Strike TA and Sheline GE: An analysis of doseeffect relationship in the radiotherapy of malignant gliomas. Int $\mathrm{J}$ Radiat Oncol Biol Phys 5: 1725-1731, 1979.

9. Andersen AP: Postoperative irradiation of glioblastomas. Results in a randomized series. Acta Radiol Oncol Radiat Phys Biol 17: 475-484, 1978.

10. Kristiansen K, Hagen S, Kollevold T, et al: Combined modality therapy of operated astrocytomas grade III and IV. Confirmation of the value of postoperative irradiation and lack of potentiation of bleomycin on survival time: a prospective multicenter trial of the Scandinavian Glioblastoma Study Group. Cancer 47: 649-652, 1981.

11. Laperriere N, Zuraw L and Cairncross G: Radiotherapy for newly diagnosed malignant glioma in adults: a systematic review. Radiother Oncol 64: 259-273, 2002.

12. Friedman HS, Kerby $\mathrm{T}$ and Calvert H: Temozolomide and treatment of malignant glioma. Clin Cancer Res 6: 2585-2597, 2000.

13. Watkins JM, Marshall DT, Patel S, et al: High-dose radiotherapy to $78 \mathrm{~Gy}$ with or without temozolomide for high grade gliomas. J Neurooncol 93: 343-348, 2009.

14. Stupp R, Hegi ME, Mason WP, et al: Effects of radiotherapy with concomitant and adjuvant temozolomide versus radiotherapy alone on survival in glioblastoma in a randomised phase III study: 5-year analysis of the EORTC-NCIC trial. Lancet Oncol 10: 459-466, 2009.

15. Crombet T, Osorio M, Cruz T, et al: Use of the humanized antiepidermal growth factor receptor monoclonal antibody h-R3 in combination with radiotherapy in the treatment of locally advanced head and neck cancer patients. J Clin Oncol 22: 1646-1654, 2004.

16. RodriguezMO,Rivero TC, del Castillo Bahi R, et al: Nimotuzumab plus radiotherapy for unresectable squamous-cell carcinoma of the head and neck. Cancer Biol Ther 9: 343-349, 2010.

17. World Health Organization Classification of Tumours. Pathology and genetics of tumours of the central nervous system. World Health Organization, IARC Press, Lyon, 2000.

18. Eisenhauer EA, Therasse P, Bogaerts J, et al: New response evaluation criteria in solid tumours: revised RECIST guideline (version 1.1). Eur J Cancer 45: 228-247, 2009.

19. Behin A, Hoang-Xuan K, Carpentier AF and Delattre JY: Primary brain tumours in adults. Lancet 361: 323-331, 2003.

20. Macdonald DR, Cascino TL, Schold SC Jr and Cairncross JG: Response criteria for phase II studies of supratentorial malignant glioma. J Clin Oncol 8: 1277-1280, 1990.

21. Berg G, Blomquist E and Cavallin-Stahl E: A systematic overview of radiation therapy effects in brain tumours. Acta Oncol 42: 582-588, 2003.

22. Hegi ME, Diserens AC, Godard S, et al: Clinical trial substantiates the predictive value of O-6-methylguanine-DNA methyltransferase promoter methylation in glioblastoma patients treated with temozolomide. Clin Cancer Res 10: 1871-1874, 2004.

23. Paz MF, Yaya-Tur R, Rojas-Marcos I, et al: CpG island hypermethylation of the DNA repair enzyme methyltransferase predicts response to temozolomide in primary gliomas. Clin Cancer Res 10: 4933-4938, 2004. 
24. Hegi ME, Diserens AC, Gorlia T, et al: MGMT gene silencing and benefit from temozolomide in glioblastoma. N Engl J Med 352: 997-1003, 2005.

25. Diaz MA, Blanco R, Garcia B, et al: Biological activity in vitro of anti-epidermal growth factor receptor monoclonal antibodies with different affinities. Hybridoma (Larchmt) 26: 423-431, 2007.

26. Ekstrand AJ, James CD, Cavenee WK, Seliger B, Pettersson RF and Collins VP: Genes for epidermal growth factor receptor, transforming growth factor alpha, and epidermal growth factor and their expression in human gliomas in vivo. Cancer Res 51: 2164-2172, 1991.

27. Bredel M, Pollack IF, Hamilton RL and James CD: Epidermal growth factor receptor expression and gene amplification in high-grade non-brainstem gliomas of childhood. Clin Cancer Res 5: 1786-1792,1999.

28. Larysz D, Kula D, Kowal M, et al: Epidermal growth factor receptor gene expression in high grade gliomas. Folia Neuropathol 49: 28-38, 2011.

29. Qin D, Ou G, Mo H, et al: Improved efficacy of chemotherapy for glioblastoma by radiation-induced opening of blood-brain barrier: clinical results. Int J Radiat Oncol Biol Phys 51: 959-962, 2001.

30. Van Vulpen M, Kal HB, Taphoorn MJ and El-Sharouni SY: Changes in blood-brain barrier permeability induced by radiotherapy: Implications for timing of chemotherapy? (Review). Oncol Rep 9: 683-688, 2002.

31. Cao Y, Tsien CI, Shen Z, et al: Use of magnetic resonance imaging to assess blood-brain/blood-glioma barrier opening during conformal radiotherapy. J Clin Oncol 23: 4127-4136, 2005.

32. Ramos-Suzarte M, Rodriguez N, Oliva JP, et al: $99 \mathrm{mTc}$-labeled antihuman epidermal growth factor receptor antibody in patients with tumors of epithelial origin: Part III. Clinical trials safety and diagnostic efficacy. J Nucl Med 40: 768-775, 1999.

33. Ramos TC, Figueredo J, Catala M, et al: Treatment of high-grade glioma patients with the humanized anti-epidermal growth factor receptor (EGFR) antibody h-R3: report from a phase I/II trial. Cancer Biol Ther 5: 375-379, 2006.

34. Giordano A, Rustum YM and Wenner CE: Cell cycle: molecular targets for diagnosis and therapy: tumor suppressor genes and cell cycle progression in cancer. J Cell Biochem 70: 1-7, 1998.

35. Petit AM, Rak J, Hung MC, et al: Neutralizing antibodies against epidermal growth factor and ErbB-2/neu receptor tyrosine kinases down-regulate vascular endothelial growth factor production by tumor cells in vitro and in vivo: angiogenic implications for signal transduction therapy of solid tumors. Am J Pathol 151: 1523-1530, 1997.

36. Kerbel RS, Viloria-Petit A, Okada F and Rak J: Establishing a link between oncogenes and tumor angiogenesis. Mol Med 4: 286-295, 1998 .
37. Gibson S, Tu S, Oyer R, Anderson SM and Johnson GL: Epidermal growth factor protects epithelial cells against Fas-induced apoptosis. Requirement for Akt activation. J Biol Chem 274: 17612-17618, 1999.

38. Lammering G, Hewit TH, Hawkins WT, et al: Epidermal growth factor receptor as a genetic therapy target for carcinoma cell radiosensitization. J Natl Cancer Inst 93: 921-929, 2001.

39. Lammering G: Anti-epidermal growth factor receptor strategies to enhance radiation action. Curr Med Chem Anticancer Agents 3: 327-333, 2003.

40. Damiano V, Melisi D, Bianco C, et al: Cooperative antitumor effect of multitargeted kinase inhibitor ZD6474 and ionizing radiation in glioblastoma. Clin Cancer Res 11: 5639-5644, 2005.

41. Diaz MA, Rolff J, Lemm M, Fichtner I, Perez R and Montero E: Radiosensitisation of U87MG brain tumours by anti-epidermal growth factor receptor monoclonal antibodies. Br J Cancer 100: 950-958, 2009.

42. Gorski DH, Beckett MA, Jaskowiak NT, et al: Blockage of the vascular endothelial growth factor stress response increases the antitumor effects of ionizing radiation. Cancer Res 59: 3374-3378, 1999.

43. Perrotte P, Matsumoto T, Inoue K, et al: Anti-epidermal growth factor receptor antibody C225 inhibits angiogenesis in human transitional cell carcinoma growing orthotopically in nude mice. Clin Cancer Res 5: 257-265, 1999.

44. Coleman CN and Stevenson MA: Biologic basis for radiation oncology. Oncology (Williston Park) 10: 399-415, 1996.

45. Bandyopadhyay D, Mandal M, Adam L, Mendelsohn J and Kumar R: Physical interaction between epidermal growth factor receptor and DNA-dependent protein kinase in mammalian cells. J Biol Chem 273: 1568-1573, 1998.

46. Kwok TT and Sutherland RM: Cell cycle dependence of epidermal growth factor induced radiosensitization. Int J Radiat Oncol Biol Phys 22: 525-527, 1992.

47. Laderoute KR, Ausserer WA, Knapp AM, Grant TD and Sutherland RM: Epidermal growth factor modifies cell cycle control in A431 human squamous carcinoma cells damaged by ionizing radiation. Cancer Res 54: 1407-1411, 1994.

48. Huang SM and Harari PM: Modulation of radiation response after epidermal growth factor receptor blockade in squamous cell carcinomas: inhibition of damage repair, cell cycle kinetics, and tumor angiogenesis. Clin Cancer Res 6: 2166-2174, 2000. 